\title{
Strategy Acquisition and Transfer Among American and German Children: Environmental Influences on Metacognitive Development
}

\author{
Martha Carr, Beth E. Kurtz, and Wolfgang Schneider \\ Max Planck Institute, Munich, Federal Republic of Germany \\ Lisa A. Turner and John G. Borkowski \\ University of Notre Dame
}

\begin{abstract}
This study explored the differential effects of strategy training on German and American elementaryschool children and assessed the role of parents in the development of their children's strategic behavior and metacognition. 184 German and 161 American children were pretested on memory and metamemory tasks. Children were then assigned to either an organizational strategy training condition or a control condition. All children were tested on the maintenance and far-transfer of the strategy and task-related metamemory 1 week following training. Parents completed questionnaires about strategy instruction in the home. Strategy maintenance and metacognition were reassessed 6 months following training. German children were more strategic than American children. Instructed children performed better than control children. German parents reported more instruction of strategies in the home. These data suggest that formal education is responsible for aspects of cognitive development that have sometimes been viewed as a function of age.
\end{abstract}

Much of memory development is not so much a product of age but of education. Schooling promotes the development of efficient memory skills that might not ordinarily occur or develop as rapidly in nonschool environments (Stevenson, 1987; Wagner, 1981). One way in which teachers and parents facilitate cognitive development is by nurturing the development of children's metacognition-their understanding about and application of learning strategies. Metacognitive knowledge enables children to benefit from instruction (Cavanaugh \& Borkowski, 1979; Schneider, Körkel, \& Weinert, 1987) and to show more durable strategy transfer (Kurtz \& Borkowski, 1987; O'Sullivan \& Pressley, 1984; Ringel \& Springer, 1980). Sophisticated metacognition is associated with superior performance in school and is especially critical in the flexible use of newly acquired strategies (Pressley, Borkowski, \& O'Sullivan, 1985; Schneider, 1985).

Although the educational orientations of European and North American schools ensure the emergence of metacognitive skills, children's strategic and metacognitive development may differ systematically across countries. In a recent investigation of German and American third graders, metacognitive knowledge about strategies and the use of a newly acquired organizational skill were the proximal causes of efficient memory performance for children from both countries (Schneider, Bor* kowski, Kurtz, \& Kerwin, 1986). Causal modeling procedures,

This research was partially supported by National Institutes of Health Grant HD-21218. Portions of the project were presented at the 1987 biennial meetings of the Society for Research in Child Development, Baltimore. The order of authorship for this article was determined randomly. Lisa A. Turner is now at the University of New Orleans.

Correspondence concerning this article should be addressed to Martha Carr, Department of Educational Psychology, University of Georgia, A.thens, Georgia 30602 however, showed a different pattern of distal causes for the two groups, and interesting differences emerged in the children's performances: German children were more strategic than Americans prior to training, whereas American children were more likely to attribute their academic outcomes to effort than were the German children. Schneider et al. (1986) hypothesized that cultural differences in strategic behaviors and attributional beliefs are tied to salient environmental factors in the home and school. This hypothesis is the focus of the present investigation.

Because characteristics of home environments are related to children's cognitive development (Gottfried, 1984), it follows that cross-national differences in parenting and teaching styles should be directly linked to individual differences in children's performances. Research has illustrated that metacognitive knowledge is enhanced in school settings by teachers who include information about how and why to use strategies as part of their regular instruction (Moely et al., 1986). Teachers show considerable variability in amount and type of strategy instruction, and some tailor their instructions to make strategies ageappropriate (Hart, Leal, Burney, \& Santulli, 1985; Moely et al., 1986). Metacognitive skills are probably further developed in school settings because the demands of school curricula accentuate the value of being strategic and of using efficient executive skills such as monitoring (Brown, 1979).

Similarly, parents' instruction at home and the problem-solving situations to which they expose their children influence the pace and pattern of children's cognitive and metacognitive development. Parents provide the groundwork for metacognitive development prior to the child's entry into school (McCombs, 1986). They influence school achievement by providing important learning experiences and encouraging their children's use of strategies (Sigel, 1982). Parents respond flexibly to their children's developing skills; for instance, they decrease the amount of on-task instruction as their children develop and internalize 
metacognitive information (Moore, Mullis, \& Mullis, 1986; Wertsch, McNamee, McLane, \& Budwig, 1980). Hence, parents can make unique contributions to their children's metacognitive development by providing enriched home environments and stimulating learning experiences.

The present study was designed to investigate the mediating role of home environments in determining the responses of young German and American children to strategy instruction. First, we assessed the benefits of an instructional package in ameliorating probable strategy differences among German and American children. We hypothesized that American children would display less sophisticated organizational-rehearsal strategies on a sort-recall task in comparison with German children but would benefit more from the strategy training. We were particularly interested in the transfer of the trained strategy and its maintenance over a 6-month period, because the phenomena of transfer and long-term maintenance require well-developed metacognition in terms of in-depth understanding of the characteristics and appropriate uses of a viable strategy. The extended time frame used to assess strategy maintenance was a stringent test of training durability as it related to metacognitive knowledge and to events in home and school environments that might facilitate strategy use and transfer. We anticipated that the strategic superiority of German children, reported by Schneider et al. (1986), would be paralleled by a higher frequency of strategy-related activities in German homes, and that within each country the quality of parental stimulation would predict strategy transfer.

\section{Method}

\section{Subjects}

One hundred and eighty-four children from Munich, West Germany, and 161 children from South Bend, Indiana, participated in the study. The mean chronological ages were $8.6(S D=.74)$ for the American children and $8.4(S D=.73)$ for the German children. Approximately half of each sample was female. Approximately $90 \%$ of the American sample and $95 \%$ of the German sample were Caucasian. Although no other demographic information was collected, we had no reason to expect that the groups differed in socioeconomic background, given that all participating classrooms were from predominantly middle-class, urban schools. All children were in the second grade during the first phase of the study.

\section{Design}

The first phase of the study consisted of five sessions. In Session 1, children were given a sort-recall memory task. A metacognitive test was administered in Session 2. At this juncture, children in each sample were randomly divided into trained groups (German $n=132$; American $n=107$ ) and control groups (German $n=52$; American $n=54$ ). During Sessions 3 and 4 , children in the experimental condition received group instructions about a four-step strategy that was useful in learning clusterable materials. Children in the control condition spent an equivalent amount of time with the experimenter and were exposed to the training materials but received no explicit instructions. In Session 5, all children were tested on the maintenance and far-transfer of the sortrecall task and answered task-related items from a metacognitive battery. Several weeks after the conclusion of Session 5, parents completed questionnaires about strategy-related experiences in the home. During
Session 6 (6 months later), children were given tests of long-term strategy maintenance and metacognition.

\section{Materials and Procedure}

All testing occurred in small groups in the children's classrooms during school hours. Sessions lasted 30 to $45 \mathrm{~min}$. A sort-recall task with pictures was administered in Session 1 . We used sets of 20 pictures of common objects that could be clustered into four groups of five pictures each (e.g., food, clothing). The labeled pictures were attached to $2 \times 2$ $\mathrm{cm}$ cardboards (with magnets affixed to the back so that they would stick to the metal boards provided by the experimenter). Children were instructed to place the pictures on the metal boards $(3 \mathrm{~min})$ and then to study them ( $2 \mathrm{~min}$ ) for later recall. Following the study period, the experimenter collected the metal boards with the pictures in place. Children were given $\mathbf{4} \mathrm{min}$ to write as many words as they remembered. The metal boards were photographed to provide a record of the children's clustering behaviors (Study ARC). Clustering scores were also derived from the children's recall protocols (Recall ARC), using the formula provided by Roenker, Thompson, and Brown (1971). The ARC (adjusted ratio of clustering) scores provided a measure of clustering that was independent of the number of items recalled, with a score of 0 indicating random clustering and a score of 1 indicating perfect clustering.

The metacognitive test was given in Session 2. The test, adapted from a battery used by Schneider et al. (1986), included items that were directly related to the sort-recall task as well as questions about other encoding and retrieval strategies. The task-specific component was made up of items that assessed children's understanding of the usefulness of clustering words into taxonomic groups as a memory aid. On five items, children designated which of two word lists they would find easier to learn. For each item, one list consisted of words that could be easily clustered into taxonomic groups; a second list consisted of unrelated, but simpler words. One point was awarded for the correct choice of the taxonomically related list. The last clustering strategy item included a set of 16 words that could be grouped taxonomically. Children ranked four possible strategies (observation, repetition, grouping by locality, and grouping taxonomically) according to usefulness $(1=$ best and $4=$ worst). Two points were awarded if the taxonomical grouping strategy was the first choice; one point was awarded if that strategy was the second choice. One extra point was awarded if the child chose grouping by locality as a second choice. A maximum possible score of eight points was possible for the six items.

The general metacognitive items measured knowledge of the ease of gist compared with rote memory for a text, reading comprehension strategies, strategies used when facing comprehension failure, memory retrieval strategies, and preparation-for-future-recall strategies. Three items - rote paraphrase, preparation object, and retrieval event-were adapted from Kreutzer, Leonard, and Flavell (1975). A comprehension monitoring item was also included, in which children underlined anything that they "did not understand" or that "did not make sense" in the text. The 97 -word text contained seven grammatical or semantic errors. One point was awarded for each incorrect phrase that the child underlined, and points were deducted for underlining correctly written text. There were 14 items in the general metacognitive subtest, with a maximum score of 27

In Sessions 3 and 4, the children were trained to cluster taxonomically. In Session 3, children in the experimental condition were taught to sort objects into categorically related groups and were shown that by doing so they would be more likely to remember the items later. Training followed the four-step study strategy developed by Gelzheiser (1984). The steps were as follows: (a) group objects taxonomically into categories, (b) name each group, (c) study the items in groups using rehearsal, and (d) cluster the items while recalling them. One week later, in Session 4 , children in the experimental condition reviewed the picture-cluster- 
ing strategy and were then taught to apply the strategy to words (e.g., grouping names or professions). Several practice trials were given, followed by feedback from the experimenter about performance accuracy. Children in the control condition were exposed to the same materials as the experimental children for an equivalent amount of time but received no training. They were asked questions about the pictures (e.g., "Do any of you have one of these animals for a pet?"), and the experimenter and children discussed responses to the questions.

Session 5 included tests of strategy maintenance and generalization as well as measurement of task-related metamemory. First, a sentence task was used to measure the children's transfer of the cluster-rehearsal strategy to a new task. All children were presented with sentences, in a random order, that were taxonomically related by subject matter (e.g., foxes are red; foxes have bushy tails). Five minutes were allowed for the children to arrange and study the sentences. A cued-recall procedure was used in which children were given keywords from each topic and were asked to write as many sentences as possible. Next, a shortened version of the metacognitive battery, which included only questions about the clustering strategy, was administered. The scoring of the taskspecific questions was the same as for the pretest task. Finally, children were tested for maintenance of the clustering strategy, using a picture test similar to that used in the pretest. For both the picture and sentence tasks, study arrangements were photographed, and ARC scores were calculated as measures of clustering behavior during the organization and rehearsal period.

Following Session 5, parents were given a questionnaire that inquired about strategy training in the home. The parent questionnaires consisted of six items that asked about in-home instruction of learning strategies for both play and schoolwork. The questions focused on two aspects of strategic behavior in the home. First, parents were asked about the number and type of strategy-related games in the home and how these games were used to instruct strategic behavior and executive skills such as performance monitoring. Second, parents were asked how they deal with their children's failure to check schoolwork and, relatedly, the frequency and manner of study-skill instruction in the home.

Six months after Session 5, the long-term effects of strategy training were assessed (Session 6). The students, who at this point had progressed into the third grade, were given a sort-recall test for long-term strategy maintenance and the complete metacognitive battery. Scoring for both tests was the same as described previously.

\section{Results}

\section{Training Effects}

Study ARC, Recall ARC, and Recall scores from pretraining, maintenance, far-transfer, and long-term maintenance are displayed in Table 1. All statistics reported were significant beyond the .05 level of significance. The 2 (country) $\times 2$ (condition) analyses of variance (ANOVAs) on pretraining Study ARC, Recall ARC, and Recall scores showed that German children were more strategic during pretraining study than were American children, $F(1,362)=9.12$. All other effects were nonsignificant.

The 2 (country) $\times 2$ (condition) analyses of covariance (ANCOVAs) on maintenance Study ARC, Recall ARC, and Recall scores, using pretraining Study ARC, Recall ARC, and Recall scores as covariates, revealed that trained children scored higher than control children on all maintenance measures, $F(1$, $338)=20.90,4.75$, and 9.83 , respectively. German children were more strategic than Americans during both study and recall, $F(1,338)=15.52$ and 15.50 , respectively. A significant Country $\times$ Condition interaction for maintenance Study ARC scores, $F(1,338)=13.80$, indicated that American children in the trained group were more strategic during study than their nontrained peers, whereas trained and control German children did not differ from one another.

The 2(condition) $\times 2$ (country) ANCOVAs on Study ARC and Recall scores at generalization, using pretraining Study ARC and Recall as covariates, showed that German children recalled significantly more items than American children, $F(1,338)=$ 16.13 , and that trained children were more strategic during study, $F(1,338)=14.61$, and recalled more items, $F(1,338)=$ 7.95 , than nontrained children in both countries. All other effects were nonsignificant.

The 2(country) $\times 2$ (condition) ANCOVAs on long-term maintenance data using pretraining Study ARC, Recall ARC, and Recall as covariates reflected that, across countries, trained children showed higher long-term Study ARC, $F(1,276)=$ 9.47, and Recall scores, $F(1,276)=10.61$, than nontrained children. Furthermore, German children outperformed American children on study strategies, recall strategies, and recall scores, $F(1,276)=28.86,22.98$, and 17.26, respectively. Significant Country $\times$ Condition interactions on long-term Study ARC, $F(1,276)=7.13$, and long-term Recall scores, $F(1$, $276)=6.58$, indicated that, for both variables, trained American children were superior to nontrained children, whereas trained and nontrained German children did not differ signifcantly across the two conditions.

In summary, training was highly successful for the American children. Trained children were more strategic and recalled more than nontrained American children at maintenance, fartransfer, and long-term maintenance. This effect was especially impressive in the long-term maintenance data. Six months after instruction, trained American children outperformed nontrained children on all measures. German children, however, were more strategic than American children during all sessions. German children in the control condition used strategies on the maintenance and long-term maintenance tests at a level comparable with that of trained children.

\section{Training and Metacognition}

Two scores were derived from the metacognitive measure, a task-specific metamemory score, which included only those items related to clustering, and a composite metamemory score, which was a summed score of task-specific and general items. Means and standard deviations of task-related metamemory appear in Table 2. To determine the effects of training on metacognitive knowledge about the clustering strategy, we conducted a 2 (country) $\times 2$ (condition) $\times 2$ (session) repeated measures ANCOVA on task-specific metamemory scores from maintenance and long-term maintenance, using pretraining task-specific knowledge as the covariate. This analysis showed that, after training, trained children showed more task-related metamemory than control children and that Germans possessed more task-specific knowledge than Americans, $F(1$, $268)=8.51$ and 15.39 , respectively. The main effect of sessions and all interactions were nonsignificant. Analyses on composite metacognitive scores showed that they did not vary systematically with training or countries.

Previous research with children in this age group has shown that general metacognitive knowledge is usually a better predic- 
Table 1

Recall, Study ARC, and Recall ARC Scores on the Sort-Recall Task as a Function of Country and Experimental Condition

\begin{tabular}{|c|c|c|c|c|c|c|}
\hline \multirow[b]{2}{*}{ Measure/condition } & \multicolumn{3}{|c|}{ United States } & \multicolumn{3}{|c|}{ Federal Republic of Germany } \\
\hline & $M$ & $S D$ & $n$ & $M$ & $S D$ & $n$ \\
\hline \multicolumn{7}{|l|}{ Pretraining Recall } \\
\hline Trained & 7.50 & 2.59 & 109 & 8.00 & 2.57 & 145 \\
\hline Control & 7.94 & 2.41 & 54 & 8.18 & 2.87 & 56 \\
\hline \multicolumn{7}{|l|}{ Pretraining Study ARC } \\
\hline Trained & .04 & .26 & 109 & .17 & .40 & 145 \\
\hline Control & .11 & .28 & 54 & .22 & .46 & 56 \\
\hline \multicolumn{7}{|l|}{ Pretraining Recall ARC } \\
\hline Trained & .22 & .54 & 109 & .24 & .54 & 145 \\
\hline Control & .19 & .50 & 54 & .17 & .55 & 56 \\
\hline \multicolumn{7}{|l|}{ Maintenance Recall } \\
\hline Trained & 11.63 & 3.71 & 107 & 11.75 & 3.48 & 135 \\
\hline Control & 10.48 & 4.35 & 54 & 10.83 & 3.56 & 54 \\
\hline \multicolumn{7}{|l|}{ Maintenance Study ARC } \\
\hline Trained & .66 & .46 & 107 & .71 & .44 & 135 \\
\hline Control & .25 & .45 & 54 & .68 & .46 & 54 \\
\hline \multicolumn{7}{|l|}{ Maintenance Recall ARC } \\
\hline Trained & .38 & .49 & 107 & .62 & .38 & 135 \\
\hline Control & .30 & .46 & 54 & .50 & .46 & 54 \\
\hline \multicolumn{7}{|l|}{ Generalization Recall } \\
\hline Trained & 62.3 & 22.00 & 112 & 68.8 & 19.40 & 130 \\
\hline Control & 53.6 & 23.50 & 55 & 67.2 & 21.50 & 51 \\
\hline \multicolumn{7}{|c|}{ Generalization Study ARC } \\
\hline Trained & .44 & .49 & 112 & .54 & .49 & 130 \\
\hline Control & .21 & .44 & 55 & .30 & .48 & 51 \\
\hline \multicolumn{7}{|l|}{ Long-Term Recall } \\
\hline Trained & 12.35 & 3.47 & 62 & 12.71 & 3.39 & 137 \\
\hline Control & 9.66 & 3.25 & 32 & 12.45 & 2.90 & 64 \\
\hline \multicolumn{7}{|l|}{ Long-Term Stuay ARC } \\
\hline Trained & .48 & .50 & 62 & .66 & .46 & 137 \\
\hline Control & .13 & .40 & 32 & .64 & .46 & 64 \\
\hline \multicolumn{7}{|l|}{ Long-Term Recall ARC } \\
\hline Trained & .28 & .38 & 62 & .53 & .42 & 137 \\
\hline Control & .20 & .41 & 32 & .47 & .33 & 64 \\
\hline
\end{tabular}

Note. ARC $=$ adjusted ratio of clustering.

tor of children's memory performance on a specific task than is the child's knowledge about strategies appropriate for that task (Schneider, 1986). Our results, presented in Table 3, were consistent with that finding: whereas most of the correlations be-

Table 2

Task-Related Metamemory

\begin{tabular}{|c|c|c|c|c|c|c|}
\hline \multirow[b]{2}{*}{ Subjects } & \multicolumn{2}{|c|}{ Pretest } & \multicolumn{2}{|c|}{ Posttest } & \multicolumn{2}{|c|}{$\begin{array}{l}\text { Long-term } \\
\text { maintenance }\end{array}$} \\
\hline & $M$ & $S D$ & $M$ & $S D$ & $M$ & $S D$ \\
\hline \multicolumn{7}{|l|}{ American } \\
\hline Trained ${ }^{a}$ & 2.52 & 1.01 & 3.08 & 1.83 & 3.19 & \\
\hline Control $^{b}$ & 2.47 & 1.46 & 2.39 & 1.79 & 2.61 & 1.38 \\
\hline \multicolumn{7}{|l|}{ German } \\
\hline Trained $^{\mathfrak{c}}$ & 3.03 & 1.33 & 3.69 & 1.48 & 3.71 & 1.37 \\
\hline Control $^{d}$ & 2.77 & 1.07 & 2.81 & 1.15 & 3.19 & 1.53 \\
\hline
\end{tabular}

tween pretraining task-specific metamemory and recall (or clustering) at maintenance, generalization, and long-term maintenance were nonsignificant, correlations between pretraining composite metamemory and task performance were generally reliable.

\section{Parental Influences on Metacognitive Development}

Items on the parent questionnaires were summed to yield a strategy score for each parent. A one-way ANOVA comparing these scores indicated that German parents $(M=15.61, S D=$ 4.58) reported more direct instruction of strategies, checked their children's work, and were more likely to use games that required strategic thinking than were American parents ( $M=$ $12.88, S D=4.19), F(1,208)=5.83, p=.017$.

In order to assess the relationship of strategy instruction to children's performances, parents' reports of strategy instruction were correlated with their children's actual recall and use of instructed strategies, within countries and within experimental conditions. Reported strategic behavior in the home for Americans was significantly related to long-term recall in the 
Table 3

Pearson Product-Moment Correlations Between Pretest

Composite Metacognition Scores and Sort-Recall

Measures for German and American Children

\begin{tabular}{|c|c|c|c|}
\hline Subjects & Maintenance & Generalization & $\begin{array}{l}\text { Long-term } \\
\text { maintenance }\end{array}$ \\
\hline \multicolumn{4}{|l|}{ German } \\
\hline \multicolumn{4}{|c|}{ Recall scores } \\
\hline Trained $^{a}$ & $.36^{* *}$ & $.48^{* * *}$ & $.33^{* *}$ \\
\hline Control $^{b}$ & $.41^{* *}$ & .17 & $.34^{* *}$ \\
\hline \multicolumn{4}{|c|}{ Study strategies } \\
\hline Trained ${ }^{\mathrm{a}}$ & $.26^{* *}$ & $.23 * *$ & $.20^{*}$ \\
\hline Control $^{b}$ & $.27^{*}$ & .18 & .02 \\
\hline \multicolumn{4}{|l|}{ American } \\
\hline \multicolumn{4}{|c|}{ Recall scores } \\
\hline Trained ${ }^{\mathrm{C}}$ & $.33^{* *}$ & $.36^{* *}$ & $.33^{* *}$ \\
\hline Control $^{d}$ & $.45^{* *}$ & $.47^{* *}$ & $.37^{*}$ \\
\hline \multicolumn{4}{|c|}{ Study strategies } \\
\hline Trainedc & .02 & $.17^{*}$ & .11 \\
\hline Control $^{\mathrm{d}}$ & $.39^{* *}$ & $.32^{* *}$ & .22 \\
\hline
\end{tabular}

a $n=133 . \quad{ }^{\mathrm{b}} n=51 . \quad{ }^{\mathrm{c}} n=111 .{ }^{\mathrm{d}} n=54$.

$* p<.05 .{ }^{* *} p<.01$.

trained group ( $r=.36$ ) but to no other measures of strategy use or recall. In contrast, reported strategic behaviors of German parents correlated significantly with study strategy use at maintenance $(r=.30)$, study strategies at long-term maintenance $(r=.32)$, and long-term maintenance recall $(r=.23)$ for trained children. Correlations between parents' reported use of strategy instruction and children's long-term composite metacognitive scores were significant for both countries: for Germans, $r=.31$, and for Americans, $r=.22$. Thus, strategy instruction in the home was related to children's metacognitive knowledge.

\section{Discussion}

This study explored systematic differences in children's performances in relation to the instructional behaviors of their parents. We explored this relationship in West Germany and the United States, hypothesizing that strategy instruction in the home would be related to cross-national differences in the use of an organizational-rehearsal strategy and associated metacognitive knowledge. Our data supported this hypothesis in three ways. First, German children were more strategic on a sort-recall task than were American children. These cross-national differences were paralleled by strategy instruction in the home: German parents reported more instruction of strategies than did American parents. Second, children's metacognition was significantly correlated with parents' strategy instruction in both countries, which was, in turn, related to strategy use, especially for German children. Finally, metacognition was associated with children's acquisition and transfer performances in both countries and paralleled differences in strategy use between countries and experimental groups.

\section{Environmental Influences on Cognitive Development}

The major assumption underlying this project-that cognitive and metacognitive development are related to specific home and school environments-received tentative support. This hypothesis was based in part on previous cross-cultural research showing that amount of schooling is predictive of strategy use, especially on school-like tasks (Sharp, Cole, \& Lave, 1979; Stevenson, Parker, Wilkinson, Bonnevaux, \& Gonzales, 1978; Wagner, 1974). It is important to recognize that the purpose of this research project was not to identify differences between German and American children; "culture" is a global variable that is difficult to define. Rather, our purpose was to determine whether individual and group performance differences might be explained by systematic differences in the instruction that children receive. Our results, which indicated that the amount and type of strategy instruction that children receive has important consequences for their task performances and metacognitive knowledge, corroborated and expanded the findings of research on schooling, as well as the conclusions of Schneider et al. (1986), who previously reported that German fourth graders were more strategic on a memory task than their American peers.

In the present study, German children at the end of Grade 2 and the beginning of Grade 3 were more strategic than American children. Although the parent questionnaire did not inquire specifically about the instruction of clustering strategies, German parents reported more general strategy instruction than American parents. Furthermore, individual differences in children's strategy use on the sort-recall task were related to the amount of strategy instruction at home for the German sample. We also distributed questionnaires to the children's teachers, inquiring about their strategy instruction in the classroom. Although the number of teachers involved (seven Americans and six Germans) was too small for meaningful statistical analyses, the overall results were consistent with the parent data: German teachers had a mean strategy score of $5.8(S D=1.47)$, compared with $4.9(S D=2.19)$ for the American teachers. Evidently, instructional practices in the home and school gave German children an advantage, resulting in superior strategy use during the early elementary grades. We adduce from these findings that German adults are more likely to understand the value of strategic actions for producing successful performance and to pass this belief on to their children at home and at school (Schneider et al., 1986).

Although the training program resulted in improved clustering and recall for American children, this was not the case for the German children. For the German group, environmental factors such as a stronger focus on strategic behavior by parents and teachers, as well as more sophisticated metamemories, likely accounted for the superior clustering and recall of both trained and control groups. The superior performance of German children at maintenance, transfer, and long-term maintenance was accompanied by more advanced task-specific metacognitive knowledge. This result is consistent with earlier studies that have indicated the importance of metacognitive information for strategy-based performance (e.g., Cavanaugh \& Borkowski, 1979; Kurtz, Reid, Borkowski, \& Cavanaugh, 1982). In the present study, advanced metacognitive knowledge and enriched strategy instruction from parents and teachers may have worked together to facilitate the use and transfer of clustering in the German sample.

The link that we found in both countries between children's 
metacognition at the long-term maintenance session and parents' reported use of strategy instruction in the home provides further evidence for the importance of environmental factors as determinants of children's cognitive and metacognitive development. Home environment, as measured using the HOME scale (Caldwell \& Bradley, 1979), has been shown to predict reading, math, and spelling achievement (Gottfried, Gottfried, \& Guerin, 1986). The results of the present study provide more specific hints about how parents influence their children's cognitive development and school performance. That is, parents in both countries who reported teaching their children strategies that are applicable to everyday situations and who possessed games that required strategic thinking had children who were higher in metacognition than peers who were from homes with less strategy-related instruction. Although it is possible that heritability mediated both factors in this correlation, we suggest that formal education-and the cultural environment in which the educational experience is embedded-are responsible for aspects of cognitive development that have sometimes been viewed as a function of age (cf. Rogoff, 1981).

\section{Implications for Instructional Practice}

We found systematic differences in children's pretraining strategy and recall performance as well as in their ensuing response to instruction. Germans were more strategic than Americans at all measurement points but did not respond to instruction as well as American children, who were more strategic at maintenance, generalization, and long-term maintenance than were American control children. This result reinforces the necessity of gearing educational programs to the specific needs and characteristics (e.g., their level of metacognitive awareness) of the children who are to be provided with strategy instructions.

Despite the variability in the training data, some tentative conclusions may be drawn about the usefulness of strategy instruction. American children in the experimental condition showed strategy use and performance that were superior to American control children at maintenance, transfer, and longterm maintenance. These data suggest that strategy knowledge that is trained over a relatively short time period can be maintained for at least 6 months. Furthermore, both German and American children in the experimental conditions generalized the use of the clustering strategy to a far-transfer task. Earlier studies have found that elaborated strategy instruction, in the form of multiple exemplars used on diverse tasks, is particularly effective in producing near generalization (Stokes \& Baer, 1977). Similarly, providing enriched metacognitive information effectively promotes generalization (cf. Pressley \& DennisRounds, 1980). It is possible, although unlikely, that the structure of the knowledge base rather than the existence of organizational strategies could be used to explain these results. A knowledge-base argument is unlikely for the following three reasons: (a) the high familiarity to all children of the test materials, (b) the dramatic gains of the American children following training, and (c) the successful transfer of the strategy by trained children from both countries on the far-transfer test (i.e., the learning of taxonomically related sentences).

Given the positive findings on the maintenance and general- ization tasks in both countries, it appears that metacognitively enriched training procedures are important for inducing transfer in young elementary-school children. Better strategy instruction in the home appeared to aid far-transfer of the organizational strategy to the sentence task. In addition, the data pointed to the important role of formal and informal learning environments for the development of metacognition and strategic performance. Future research should identify the unique impacts of specific parenting and teaching techniques that enhance metacognitive development. Cross-cultural research may be particularly helpful to this end, in that it provides a broader base for the comparisons of both group and individual differences and sometimes magnifies culturally related interactions that transpire in living rooms or classrooms.

\section{References}

Brown, A. L. (1979). Theories of memory and the problem of development: Activity, growth, and knowledge. In L. S. Cermak \& F. M. Craik (Eds.), Levels of processing in human memory (pp. 225-258). Hillsdale, NJ: Erlbaum.

Caldwell, B. M., \& Bradley, R. H. (1979). Home observation for measurement of the environment. Little Rock: University of Arkansas.

Cavanaugh, J. C., \& Borkowski, J. G. (1979). The metamemory-memory "connection": Effects of strategy training and maintenance. Journal of General Psychology, 101, 161-174.

Gelzheiser, L. (1984). Generalization from categorical memory tasks to prose by learning disabled adolescents. Journal of Educational Psychology, 76, 1128-1139.

Gottfried, A. W. (1984). Issues concerning the relationship between home environment and early cognitive development. In A. Gottfried (Ed.), Home environment and early cognitive development (pp. 1-4). London: Academic Press.

Gottfried, A. E., Gottfried, A. W., \& Guerin, D. (1986, April). Environmental predictors of cognitive development and early school success: A longitudinal study. Paper presented at the annual meetings of the American Educational Research Association, San Francisco.

Hart, S. S., Leal, L., Burney, L., \& Santulli, K. A. (1985, April). Memory in the elementary-school classroom: How teachers encourage strategy use. Paper presented at the meetings of the Society for Research in Child Development, Toronto.

Kreutzer, M. A., Leonard, C., \& Flavell, J. H. (1975). An interview study of children's knowledge about memory. Monographs of the Society for Research in Child Development, 40 (Serial No. 159).

Kurtz, B. E., \& Borkowski, J. G. (1987). Development of strategic skills in impulsive and reflective children: A longitudinal study of metacognition. Journal of Experimental Child Psychology, 43, 129-148.

Kurtz, B. E., Reid, M. K., Borkowski, J. G., \& Cavanaugh, J. C. (1982). On the reliability and validity of children's metamemory. Bulletin of the Psychometric Society; 19, 137-140.

McCombs, B. L. (1986, April). The role of the self-system in self-regulated learning. Paper presented at the annual meetings of the American Educational Research Association, San Francisco.

Moely, B. E., Hart, S. S., Leal, L., Johnson, T., Rao, N., \& Burney, L. (1986). How do teachers teach memory skills? Educational Psychologist, 2l, 55-71.

Moore, J. J., Mullis, R. L., \& Mullis, A. K. (1986). Examining metamemory within the context of parent-child interactions. Psychological Reports, 59, 39-47.

O'Sullivan, J. T., \& Pressley, M. (1984). Completeness of instruction and strategy transfer. Journal of Experimental Child Psychology, 38, 275-288.

Pressley, M., Borkowski, J. G., \& O'Sullivan, J. (1985). Children's meta- 
memory and the teaching of memory strategies. In D. L. ForrestPressley, G. E. MacKinnon, \& T. G. Waller (Eds.), Metacognition, cognition, and human performance (pp. 111-154). New York: Academic Press.

Pressley, M., \& Dennis-Rounds, J. (1980). Transfer of a mnemonic keyword strategy at two age levels. Journal of Educational Psychology $72,575-582$.

Ringel, B. A., \& Springer, C. J. (1980). On knowing how well one is remembering: The persistence of strategy use during transfer. Journal of Experimental Child Psychology, 29. 322-333.

Roenker, D. L., Thompson, C. P., \& Brown, S. (1971). Comparison of measures for the estimation of clustering in free recall. Psychological Bulletin, 76, 45-48.

Rogoff, B. (1981). Schooling and the development of cognitive skills. In H. C. Triandis \& A. Heron (Eds.), Handbook of cross-cultural psychology (Vol. 4, pp. 233-294). Boston: Allyn \& Bacon.

Schneider, W. (1985). Developmental trends in the metamemory-memory behavior relationship: An integrative review. In D. L. ForrestPressley, G. E. MacKinnon, \& T. G. Waller (Eds.), Cognition, metacognition, and human performance (Vol. 1, pp. 57-109). New York: Academic Press.

Schneider, W. (1986). The role of conceptual knowledge and metamemory in the development of organizational processes in memory. Journal of Experimental Child Psychology, 42, 218-236.

Schneider, W., Borkowski, J. G., Kurtz, B. E., \& Kerwin, K. (1986). Metamemory and motivation: A comparison of strategy use and performance in German and American children. Journal of Cross-Cultural Psychology, 17, 315-336.

Schneider, W., Körkel, J., \& Weinert, F. E. (1987). The effects of intelligence, self-concept, and attributional style on metamemory and memory behavior. International Journal of Behavioral Development, 10, 281-299.

Sharp, D., Cole, M., \& Lave, C. (1979). Education and cognitive development: The evidence from experimental research. Monographs of the Society for Research in Child Development, 44, (Serial No. 178).

Sigel, I. E. (1982). The relationship between parental distancing strategies and the child's cognitive behavior. In L. M. Laosa \& I. E. Sigel (Eds.), Families as learning environments for children (pp. 47-86). New York: Plenum Press.

Stevenson, H. W. (1987). Culture and schooling: Influences on cognitive development. In E. M. Hetherington, R. Lerner, \& M. Perlmutter (Eds.), Child development and a life-span perspective (pp. 241-258). Hillsdale, NJ: Erlbaum.

Stevenson, H. W., Parker, T., Wilkinson, A., Bonnevaux, B., \& Gonzalez, M. (1978). Schooling, environment, and cognitive development: A cross-cultural study. Monographs of the Society for Research in Child Development, 43, (Serial No. 175).

Stokes, T. F., \& Baer, D. M. (1977). An implicit technology of generalization. Journal of Applied Behavior Analysis, 10, 349-367.

Wagner, D. (1974). The development of short-term and incidental memory: A cross-cultural study. Child Development, 45, 389-396.

Wagner, D. A. (1981). Culture and memory development. In H. C. Triandis \& A. Heron (Eds.), Handbook of cross-cultural psychology: Developmental psychology (Vol. 4, pp. 187-232). Boston: Allyn \& Bacon.

Wertsch, J. V., McNamee, G. D., McLane, J. B., \& Budwig, W. A. (1980). The adult-child dyad as a problem-solving system. Child Development, $51,1215-1221$.

Received February 12, 1988

Revision received December 2, 1988

Accepted January 24, 1989 